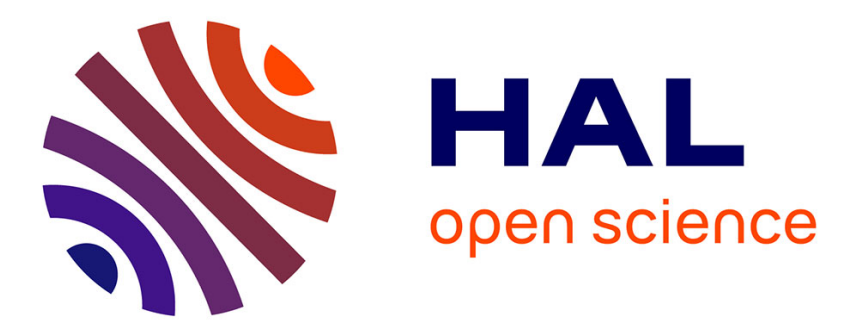

\title{
An Economic Insight into Additive Manufacturing System Implementation
}

Milad Ashour Pour, Massimo Zanardini, Andrea Bacchetti, Simone Zanoni

\section{To cite this version:}

Milad Ashour Pour, Massimo Zanardini, Andrea Bacchetti, Simone Zanoni. An Economic Insight into Additive Manufacturing System Implementation. IFIP International Conference on Advances in Production Management Systems (APMS), Sep 2015, Tokyo, Japan. pp.146-155, 10.1007/978-3-31922759-7_17 . hal-01431088

\section{HAL Id: hal-01431088 \\ https://hal.inria.fr/hal-01431088}

Submitted on 10 Jan 2017

HAL is a multi-disciplinary open access archive for the deposit and dissemination of scientific research documents, whether they are published or not. The documents may come from teaching and research institutions in France or abroad, or from public or private research centers.
L'archive ouverte pluridisciplinaire HAL, est destinée au dépôt et à la diffusion de documents scientifiques de niveau recherche, publiés ou non, émanant des établissements d'enseignement et de recherche français ou étrangers, des laboratoires publics ou privés. 


\title{
An Economic Insight into Additive Manufacturing System Implementation
}

\author{
M. Ashour Pour, M. Zanardini, A. Bacchetti, S. Zanoni \\ Department of Mechanical and Industrial Engineering, University of Brescia \\ Via Branze, 38 - 25123 - Brescia, Italy \\ email: m.ashourpoureunibs.it - massimo.zanardini@unibs.it - \\ andrea.bacchetti@unibs.it - simone.zanoni@unibs.it
}

\begin{abstract}
With an ever growing diffusion of Additive Manufacturing (AM) system in industrial and commercial level, as well as the direct and indirect dynamics which are being introduced resulting from its inclusion as a possible production technology on companies' portfolio, the need to reconfigure production system and adapt the production strategy becomes even more relevant than before. There are several studies which have emphasized on the importance of a paradigm shift in order to exploit advantages of AM, not only considering changes within design and functionality of the product, but also concerning AM's impact on the entire value chain (re)configuration. Thus, it is of crucial importance to take into consideration that for this shift to be feasible and manageable, there is a need to include both technical and managerial aspects of manufacturing. This work proposes an economic insight in order to provide a guideline for the proper evaluation of AM system implementation.
\end{abstract}

Keywords: Additive Manufacturing, Economic Assessment, Implementation Guideline.

\section{Introduction}

Considering their evolution rate, Additive Manufacturing (AM) technologies are becoming more interesting for a growing spectrum of industries, and the applications will soon impact the production activities of components and products [1] as well. The authors have found that the scarce available literature is not aligned with companies' requirements. They are focusing mostly on technological aspects, and do not provide an holistic view to ensure the evaluation of all the benefits and limitations of AM. In order to highlight the main limitations, three categories have been identified: (i) The data provided are often not up to date (and generally refer to a particular technology or even to a particular machine); (ii) The majority of the works consider a specific technology, and do not provide a priori analysis for identifying which is the most suitable for the context of application; (iii) As a consequence of point $i i$, the economic analysis generally does not compare different AM technologies to evaluate which is the best one and thus, no investment decision analysis is considered.

In order to overcome the shortcomings described above, this work provides an holistic guideline; deploying an economic analysis to properly investigate the use of AM technologies within an industrial sector. The main objectives can be summarized as the following:

- To define a guideline to support manufacturing companies to understand whether AM techniques are suitable for their context and products; proposing criteria for implementing an a priori analysis, and providing a list of the (eventual) appropriate technologies and related machines, 
- To provide a model to include economic implications resulting from AM application, facilitating a comparison between conventional subtractive techniques.

\section{$2 \quad$ AM system}

In order to have a better understanding of AM, it is necessary to look at it from the system point of view. This is due to the wide range of impacts that is accompanied by its implementation: extending from raw material suppliers and procurement, towards production level, distributors and even customers. Furthermore, a systematic analysis is able to characterize AM in a more comprehensive way. AM is a term applied to a technological class which consists of multiple subsets that make up the technological variations. Each of these technologies could be applied in various industries ranging from electronics to medical, automotive, armament and aerospace.

\subsection{AM Characterization}

One of the most remarkable aspects of AM which has enhanced its position among other manufacturing techniques is the flexibility, not only enabling economical low volume production[2] by eliminating the need for tooling, but also providing designers with a degree of freedom that no more limits functionality in favor of feasibility of the process. This feature provides manufacturers with two remarkable opportunities regarding the design: faster time-to-market, and almost real-time design changes that happen as improvements and optimizations are made to the original design. According to [3], special features of AM would result in the following benefits:

- Tool independency, since no tooling is required,

- Economic production of small batches becomes feasible,

- High flexibility for changing the design of the parts/products,

- Optimization for product functionality would be achievable,

- Customization of products which are based on individual customers' needs,

- High possibilities of wastes elimination during production phase,

- Possibility of having simpler and shorter supply chains.

Another study [4] characterizes AM by highlighting its distinguishing features. High automation and part consolidation which provides the possibility to build parts as a single piece and therefore eliminate the assembly would consequently lead to a great reduction of the labor, storage, handling and logistics costs. Economies of scale are one of the most remarkable properties of mass manufacturing. Manufacturing in large volumes allows for reduction of cost per unit as a result of the fixed-cost proration. However, since AM machinery requires no setups, production in small batches becomes economically feasible and this is a direct result of "economies of one".

Economic inefficiency in large volume production, inability of processing large parts due to the chamber size limitations [5], process variability [4] and lack of consistency among produced parts to ensure mechanical properties of the parts [6], incompetency of the companies struggling with process automation and digitalization, limited range of raw materials and lack of international standardization are amongst the most important barriers towards considering AM as manufacturing method. 


\subsection{AM technology variations}

Different approaches have been introduced to classify AM processes. One classification is based on the raw materials feed. While it classifies processes according to four types of input raw materials, another type of classification is based solely on the working principle of process [6]. Amongst the others, the most comprehensive classification is presented by the AM subset of American Society for Testing and Materials (ASTM F42), categorizing AM variants into seven broad groups [6].

The notable areas in which AM has been deployed with high rates of success are currently limited to medical devices, consumer goods (e.g. electronics), aerospace, automotive, jewelry, architecture and defense [2]. Although various studies have considered the issue of energy usage in AM machines, a unified and standard procedure to measure energy consumption is still lacking and there needs to be more data for making comparisons among conventional technologies and AM. However, there are multiple studies [7] which show when it comes to the environmental aspects and carbon footprint, AM has a positive impact. Needless to say that a majority of these researches would still pinpoint the focus of their investigations into the lack of detailed information regarding wastes, energy consumption and environmental impacts.

\section{Impactful dynamics of AM}

As it was mentioned earlier, AM is a system which is attributed by a variety of dynamics. One of these attributes which directly impacts the value chain is the supply chain management. The ability to redesign products with fewer components and the possibility of manufacturing products near customers' physical location are two valuable opportunities offered by AM [5]. This would not only reduce the need for warehousing, transportation and inventory, but it would also make the supply chain simpler by reducing time-to-market and lead-time. Design for Additive Manufacturing (DFAM) is a term which is used to emphasize on the flexibility of AM; meaning that since there are no limitations imposed by the design of the product to reduce its functionality, parts can be redesigned into single components and thus, AM's capabilities would be exploited in a more efficient way. By doing so, a reduction of the materials, energy and natural resources would take place which would eventually result in significant sustainable and economic benefits. An exciting area for AM to implement is in the spare parts supply chain. A thorough investigation [8] of spare parts supply in aircraft industry shows that rapid manufacturing (a term used for AM of individual parts/small lot sizes) can be used for low volume production of parts in a centralized location and at the place of consumption, if inventory holding and logistics costs are high in comparison with the production costs. This strategy would keep stock level down and AM capacity utilization high. In another study [9] four scenarios were studied in two dimensions of supply chain configuration (centralized and decentralized) and AM machine technology (current and future technology). One significant outcome of the study showed that with the current maturity of AM in which machines are both capital- and labor-intensive, centralized production is more efficient, while with the evolution of technology in the future, characterized by cheaper and more automated machines, distribution of production would be a better choice for the spare parts supply chain. 
Although the lack of comprehensive data to assess sustainability aspects of AM is a big impediment, some researchers have tried to identify the key concepts of AM which are relevant to sustainable manufacturing [7]. These are the same advantages that distinguish AM from conventional and traditional manufacturing processes. Considering the current legislation and regulatory laws that exist on the environmental aspects of manufacturing processes, and manufacturers' tendency towards moving to cleaner and more sustainable production, the environmental impacts of AM is part and parcel of any analytic assessment. An analytic model on the evaluation of environmental impacts in AM [10] which considered the whole environmental flows, shows that in order to study the global environmental impacts, not only the electricity power consumption, but also the materials, and fluid consumption need to be taken into account.

\section{State of the art of AM adoption frameworks}

One of the first contributions in this research stream comes from[11] that provided a model for cost estimation of AM applications. It analyzes the direct cost of production considering the machine, labor, and material costs, omitting the overhead costs, as well as the energy consumption. One of the most relevant outputs of the work is evaluation of the typical 3D printing cost profile, which is independent from quantity of the production. In the subsequent studies, the results are discussed in detail and then confuted, especially for small production batches.

The use of activity-based costing for the economic analysis of an AM alternative is provided by [12], however the proposed model has strong limitations since it considers only one single technique. Nevertheless, [12] confirmed previous assumptions, meaning that the more production chamber is saturated, the more the unit cost production is reduced. The models provided in the following years [13] try to evaluate cost of $3 \mathrm{D}$ printing application in an holistic view, considering a life cycle approach. In these works, the authors encompassed also re-designing activities which are required for a full exploitation of 3D printing capabilities, while incorporating full advantages enabled by AM. The approach considered by [14] is one of the most comprehensive ones. First, they identify a list of possible products that may be revisited by AM, for each of which, they then evaluate the most appropriate technology that matches the firm's requirements, and only at the end of this evaluation process, do the authors develop an economic analysis.

Considering a more consultancy-oriented approach, one has to notice Senvol (included in [1]), the company which experts in AM machinery and applications based in the US. In the paragraph titled "Cost-Benefit Analyses for Final Production Parts", the authors explain applications of their cost evaluation model. Contrary to the previous works cited earlier (e.g. [11]\&[12]), and due to the inefficiencies caused by print batches, their model does not provide a constant production cost. Thus, until the printing chamber is not completely saturated, the production cost per part provided is not constant. Considering the assumption that the more the machine is saturated, the lower the final production cost per part, previous scientific works that hypothesize to fully load the printer capacity seem more attractive. This assumption is reasonable, taking into account that (due to the absence of setup costs) a given company could 
saturate the build chamber with other parts/products and hence produce with a fully saturated chamber.

\section{Evaluation guideline and case study}

According to [15], one of the main requirements of companies with respect to AM is the analytic support in order to evaluate whether or not AM could be suitable for their production processes and products. In this era, academics have to propose guidelines that help "senior management to reconsider whether they will continue using current production technologies, or they could benefit by exploiting the benefits of modern AM technologies". In accordance with this statement, the authors have identified a logical path that a company which is approaching AM for the first time, could follow in order to have a comprehensive evaluation of the AM techniques (Error! Reference source not found.).

Fig. 1. Proposed AM evaluation framework

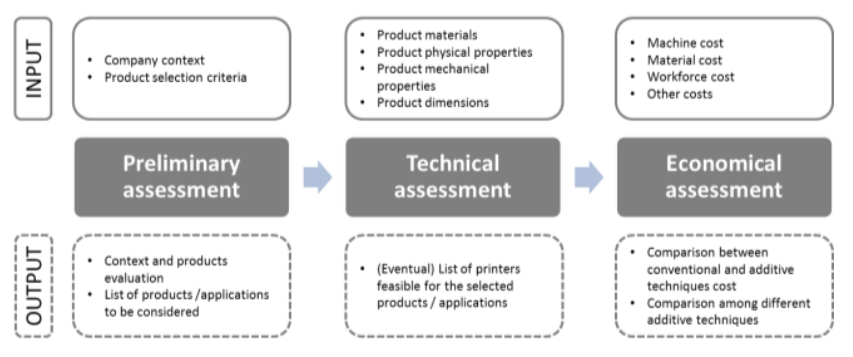

Reminding the main shortcomings described in the introduction section, the guideline aims to provide a complete assessment of this new paradigm; considering not only an economic evaluation or a context/product analysis, but also a comprehensive assessment of the alternative AM technologies that can be employed. The text provides an a priori analysis of the AM applications, considering the main features of the company context and products properties, and then proposes a technical and economic model to provide data for a quantitative assessment.

\subsection{Preliminary assessment}

The first step that a company should take to understand whether these technologies may bring advantage to its business is a preliminary (qualitative) assessment of the context in which it operates. A framework provided by [16] encompasses three key attributes: production volume, customization, and complexity of the products.

The cited works do not provide quantitative drivers for an easy evaluation of which products are more promising for AM. Indeed, it is argued that already in this preliminary step a company should consider indicators related both to product and supply chain features for identifying which products (or range of products) could be encompassed in the following evaluation steps. For this reason, four different quantitative drivers are introduced that permit a selection of the most promising products for AM:

$$
\begin{aligned}
& \text { Cost weight intensity }=\frac{\text { Product overall cost }[€]}{\text { Product weight }[\mathrm{kg}]}(1) \\
& \text { Buy to fly }=\frac{\text { Total material consumption }[\mathrm{kg}]}{\text { Product weight }[\mathrm{kg}]}(2)
\end{aligned}
$$


Mould cost intensity $=\frac{\text { Cost of the mould allocated to the product }[€]}{\text { Product overall cost }[€]}(3)$
CNC time intensity $=\frac{\text { CNC time consumption }[\mathrm{h}]}{\text { Product volume }\left[\mathrm{dm}^{3}\right]}(4)$

In which, the higher the ratios, the more appropriate AM alternative would be.

\section{Technical assessment}

The next evaluation phase takes the input from selected products of the last part, aiming at the evaluation of the technological feasibility to manufacture them through AM. A more quantitative analysis is performed in order to map some relevant product features that have to be considered in this technological assessment; including dimensions, materials, physical and mechanical properties etc. The comparison of these parameters with a machines' database ensures to identify the (eventual) technologies and the related machines that are suitable for the company's products and needs. The output of this step is a list of (technology and) machines that fulfill the company's requirements, along with information about the machinery price as well as the retailers that could provide them.

\section{Economic assessment}

Having identified the list of suitable machines, it is possible to perform a preliminary evaluation of the costs incurred by the company. The developed model ensures two different types of analysis: one for evaluating whether products or components made by AM are more cost-effective than the same products or components realized through conventional subtractive techniques (e.g. injection molding or CNC machining), and the other one for evaluating which of the AM technologies that fulfill company's needs is more cost-effective, overcoming a general limitation of the literature.

According to [11], the provided model computes the direct costs of the AM application in terms of machine, materials and workforce. Indeed, thanks to the rigorous data collection, the costs related to the maintenance activities that [12] took into account as indirect cost, is considered to be a direct cost.

\subsection{Case study}

The proposed case study considers a company that has exploited AM since 2001, and reached a high level of expertise, especially in SLA [6]. The company belongs to the automotive sector (specialized in the production of racing components), and operates following an Engineer-To-Order strategy in a one-of-a-kind-production context.

Initially, the SLA technology is compared with SLS [6], and due to several reasons, SLA has been selected as the most appropriate choice. First of all, the company considered the liquid material (raw material for SLA) easier to manage (than the powder required for SLS). Secondly, the durability of the products (longer for SLS) was not required, since the prototypes are used no longer than one month. These requirements have been changed in the last years, and so the company needs to reevaluate the available technologies. The company's choices are limited to SLA and SLS technologies, since other AM variants produce products whose technical characteristics wouldn't match with those of the company and its customers. Thus, the company is happy with limiting its range of selection to these two AM variants.

According to the guideline described before, the company context is first considered for a preliminary analysis. After the positive qualitative results, the proper tech- 
nologies for the specific requirements are identified and then an economic analysis of the selected technologies (and printers) is performed.

Having already discussed with $R \& D$ department and wind tunnel managers in order to analyze the main product features as well as the company's specialty, the company is understood to be operating in a one of a kind production sector, where each product is realized upon specific customers' requirements and needs. Considering the quantitative drivers introduced above, (at least) two of them are considered relevant for AM evaluation:

- For the majority of the products and prototypes realized, the buy-to-fly ratio is very high (exploiting conventional casting and molding technologies) according to the hollow structure required,

- And considering the uniqueness of the products, the mold cost intensity is also very high, in accordance with the allocation of the mold cost to only one product manufactured.

Considering these two drivers, and in response to the high levels of product complexity and customization, as well as the low volume productions, the company context immediately appears to be highly suitable for AM application. Once the evaluation of the preliminary feasibility study of AM techniques is performed for the products, the next step i.e. the technical assessment is started, through which it becomes possible to identify which technologies are able to satisfy company's requirements. Taking into account products' dimensions, surface finish, mechanical properties, and the required production volume (data collected through interviews with R\&D manager), the technical database is consulted to exhaust all the available options: not surprisingly, the output provides 15 printers using SLA and SLS technologies for polymer materials. These technologies ensure an appropriate level of product porosity, which is one of the main requirements for the company (even though SLA reaches better performance levels related to this parameter). The technical database provides: 6 printers out of 15 exploit SLA technology (differing only in the chamber's dimensions), while the remaining 9 printers make use of SLS technology for manufacturing parts.

According to the proposed guideline and using the collected data, an economic evaluation is then performed to compute the total production cost for all 15 printers. In the remainder of the paper the data for two analyses are discussed: one related to the SLA technology (the iPro800 printer which is the actual one adopted by the company), in order to validate the model, and one related to the SLS technology, in order to evaluate an alternative scenario (considering the most advanced printer coming from previous step, that is the Spro140 HD by 3D Systems).

In the first analysis in which the company's 3D printing cost structure (given by the interviewed personnel) is compared with the value computed by the proposed model, an initial model validation is obtained: the output approximates the actual cost given by the company with high accuracy ( $>95 \%)$. So, in a preliminary way, it is assumed that the model adequately represents the behavior of the real system for the project objectives. Then the model is modified in a way to estimate the SLS printing process cost structure (according to the 3 cost elements described earlier). As a result, an evaluation of the performances in the as-is and to-be scenarios is obtainable. The comparison between SLS and SLA model outputs, highlights lower overall cost for 
SLS, with a global saving of more than $€ 300,000$ per year (about $25 \%$ reduction). In Error! Reference source not found. a comparison of the cost structures for as-is and to-be scenarios is illustrated.

Fig. 2. Economic analysis of as-is and to-be scenarios

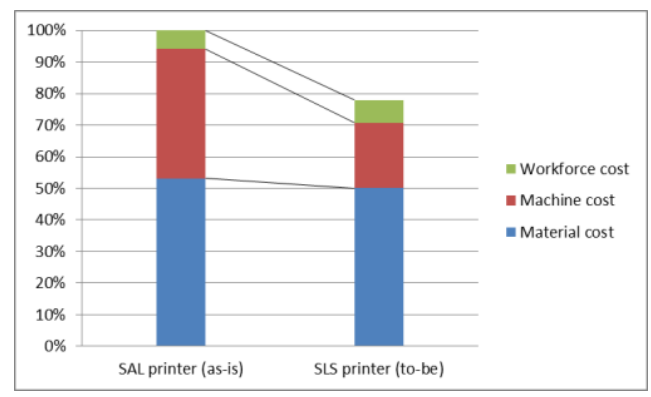

- Material cost is lower for SLS, considering that higher waste rate of this technology is balanced out with cost per kg of raw materials, which is roughly half compared with SLA.

- Machine cost is higher for SLA, and constituted the majority of the gap between the overall costs of the two technologies. This is due to the stacking parameter: SLA does not permit to stack up different products on different layers, while SLS (that exploits powder material) ensures to fully saturate the printing chamber with different layers of products. For this reason SLA technology requires more printers to fulfill the annual demand of products than SLS does. In particular, SLA requires 6 printers while SLS needs only 2.

- Work cost is similar for the two technologies. SLS requires more time for finishing operations, while SLA requires longer time for the setup activities.

Considering that the evolution of SLA and SLS technologies has enhanced precision and resolution of these technologies onto very high (and almost similar) levels, the decision concerning which of them to implement is closely related to the total manufacturing process cost. Therefore, taking into account the economic assessment provided, and the strategic alternative about the technical performance of the two technologies, the company is now evaluating the possibility to (gradually) change its technology and substitute the old SLA machine with a new SLS machine.

\section{Conclusion}

There are two points about AM that draws a lot of attention among concerning researchers in the field. First, the rather young age of AM compared with the traditional and conventional technologies and second, the ongoing process towards full adoption of AM as a viable manufacturing system in the industrial world. However, it must be noted that due to the incomplete maturity and ongoing research, many of AM's aspects including, but not limited, to process measurement and standardization, finish surface quality, throughput rate, raw material selection, still lack enough competence to replace conventional technologies and become a widely accepted manufacturing system. In order to define a more holistic approach to AM, implementation of more case studies and accurate tests deem necessary to provide guidelines which help to 
identify the threshold value for the abovementioned four drivers to immediately discriminate which products should be subjected to a technical and economic evaluation, and which should be excluded from further analysis.

\section{References}

[1] T. Wohler, "Wohlers Report," 2014.

[2] S. Mellor, L. Hao, and D. Zhang, "Additive manufacturing: A framework for implementation,” Int. J. Prod. Econ., vol. 149, pp. 194-201, Mar. 2014.

[3] J. Holmström, J. Partanen, J. Tuomi, and M. Walter, "Rapid manufacturing in the spare parts supply chain: Alternative approaches to capacity deployment," J. Manuf. Technol. Manag., vol. 21, pp. 687-697, 2010.

[4] P. A. Mattia Bianchi, "Additive manufacturing: towards a new operations management paradigm ?," vol. 2020, pp. 1-10.

[5] S. H. Huang, P. Liu, A. Mokasdar, and L. Hou, "Additive manufacturing and its societal impact: a literature review," Int. J. Adv. Manuf. Technol., vol. 67, no. 5-8, pp. 1191-1203, Oct. 2012.

[6] N. Guo and M. C. Leu, "Additive manufacturing: technology, applications and research needs," Front. Mech. Eng., vol. 8, no. 3, pp. 215-243, May 2013.

[7] M. Mani, K. W. Lyons, and S. K. Gupta, "Sustainability Characterization for Additive Manufacturing," vol. 119, pp. 419-428, 2014.

[8] M. Walter, J. Holmström, and H. Yrjölä, "Rapid manufacturing and its impact on supply chain management," 2004.

[9] S. H. Khajavi, J. Partanen, and J. Holmström, "Additive manufacturing in the spare parts supply chain,” Comput. Ind., vol. 65, no. 1, pp. 50-63, Jan. 2014.

[10] F. Le Bourhis, O. Kerbrat, J. Hasco, P. Mognol, and P. M. Sustainable, "Sustainable manufacturing : evaluation and modeling of environmental impacts in additive manufacturing To cite this version :," 2013.

[11] N. Hopkinson and P. Dickens, "Analysis of rapid manufacturing - using layer manufacturing processes for production," Mech. Eng. Sci., vol. 217, pp. 3139, 2003.

[12] R. H. M Ruffo, Christopher Tuck, "Cost estimation for rapid manufacturing laser sintering production for low to medium volumes," 2006.

[13] A. S. Elenora Atzeni, "Economics of additive manufacturing for end-usable metal parts," Int. J. Adv. Manuf. Technol., vol. 62, no. 9-12, pp. 1147-1155, 2012.

[14] A. B. Kair and K. Sofos, "Additive Manufacturing and Production of Metallic Parts in Automotive Industry: A Case Study on Technical , Economic and Environmental Sustainability Aspects."

[15] C. Achillas, D. Aidonis, E. Iakovou, M. Thymianidis, and D. Tzetzis, “A methodological framework for the inclusion of modern additive manufacturing into the production portfolio of a focused factory," J. Manuf. Syst., Aug. 2014.

[16] B. P. Conner, G. P. Manogharan, A. N. Martof, L. M. Rodomsky, C. M. Rodomsky, D. C. Jordan, and J. W. Limperos, "Making sense of 3-D printing: creating a map of additive manufacturing products and services," Addit. Manuf., vol. 1-4, pp. 64-76, Sep. 2014. 